\title{
Journal of Lumbini Medical College Editorial Policy
}

\section{GENERAL POLICY}

1. Journal of Lumbini Medical College Journal (JLMC) is a biannually Scientific Medical Journal published in English by Lumbini Medical College in Palpa, Nepal. The Journal is printed in two column format. Its publication is supported by patron fee, commercial advertisement.

2. Subjects covered include all aspects of health and diseases including clinical and experimental studies and medical education (in the form of original full papers, short communications, critical reviews, editorial commentaries, conference summaries and book reviews).

3. Manuscripts in English from investigators/authors from any institutions in any country are considered. The results and ideas contained therein should be original.

4. Three sets of manuscript (one original and two copies) accompanied by a covering letter signed by first author should be submitted to The Editor, Journal of Lumbimi Medical College (JLMC), Lumbini Medical College, Tansen 11, Pravas, Palpa, Nepal; Email: Imcpalpa@gmail.com. The covering letter should clearly state that the manuscript has not been submitted for consideration and will not be submitted in any other Journal till the manuscript remains under consideration for publication in JLMC.

5. All persons designated as authors should qualify for authorship. Each author must have at least bachelor degree in the related field and should have participated sufficiently in the work to take the public responsibility for the content. A paper with corporate (collective) authorship must specify the key person responsible for the article.

6. Articles for publication will only be accepted after getting signed declaration from the author that the manuscript has not been submitted elsewhere for publication.

7. If the instructions are not followed, the manuscripts will be returned to the authors for appropriate modification.

8. Manuscripts meeting the editorial policy will be sent to two anonymous peer reviewers. The suggestion and/or comments of peer reviewers will be communicated to the author for necessary revision/ modification/information.

9. Upon acceptance, authors should submit the whole text of manuscript revised as per the advice or comments of peer reviewers and/or Editorial Board in IBM compatible.

10.The galley proofs of the articles will be sent to the corresponding authors for minor corrections and must be returned(reached) to the Editor within one month time(from the date of dispatch). Major alterations (even and addition or deletion of single sentence) will not be accepted.

11.If the manuscript is accepted for publication and published, the paper or the portion there of, will not be published elsewhere unless the consent is obtained in writing from editor of JLMC.

12. The final decision of whether to publish is made by the Editorial Board.

\section{PREPARATION OF MANUSCRIPT}

1. Format: The whole test including references should be typed or printed by a good quality printer in double space with margins of at least one inch on both sides. The manuscript should be arranged in this order: (1) Title page, (2) Abstract and Key words, (3) Text (Introduction, Materials and Methods, Results, Discussion and Conclusion), (4) Acknowledgements, (5) References, (6) Tables, (7) Figures and (8) Legends.

2. Title page: This should carry (1) a concise but informative title of the paper, (2) the full name of each author(s) with highest academic degree and institutional affiliation, (3) running title (in less than 40 letters), (4) address for correspondence about the articles and for the reprint request and (5) disclaimers, if any.

3. Abstract: The second page should carry an abstract of not more than 250 words. It should include objectives and rationale of the study, methods used, main findings and significance of finding. It should be accompanied by 3-6 key words.

4. Text: The text should be divided into (1) Introduction, (2) Materials and Methods in sufficient detail, (3) Results and (4) discussion (including conclusion) and should be written in capital letters. No 'Tabs' are given I the text. Findings should be analysed by 
statistical methods and be well interpreted showing level of significance.

5. Acknowledgements: All acknowledgements including financial support should be mentioned under this heading.

6. References: The number of references should be in consecutive order in which they are first mentioned in the text. The references in the text should be identified by Arabic numerals as superscript. The list of references should be in Vancouver System and the name of journal should be abbreviated in accordance with the Index Medicus and should be in Italic.

\section{EXAMPLES:}

A. Standard Journal Article (including review articles): List all authors when three or less: when four or more, list only first three and add et al.

- Phorkuntham U, Piyawinijwong S, Pilakasiri K, Rojananin J. The infraorbital foramen in Thais. Siriraj Hosp Gaz 1985; 37: 277-82.

B. Research Notes, Short communication, Letters to the Editor and Editorials: The pattern should be the same as the of standard Journal article but with mention of research notes, short communication, letter to the editor and editorials accordingly in the parenthesis (after the title)

- Uga S, Morimoto M, Saito T, RaiSK. Surface ultrastructure of Heterophyes heterophyes (Trematoda: hetrophyidea) collected from a man (Research Note) J Helminthol Soc Was 1998; 65: 119-22.

\section{Corporate Author in Journal:}

Ghana Vast Study Team. Vitamin A supplementation in northern Ghana: effects on clinical attendance, hospital admissions and mortality. Lancet 1993; 343: 7-12.

Note: Supplement volume or issue of a Journal should be indicated by "Suppl" in parenthesis after the publication year [for example, Brit Med J 1990 (Suppl); 13: 121-5]

\section{Personal Author in Book:}

- Oslen OW. Animal parasited - Their Life cylces and Ecology. 3rd ed. Baltiore-London -Tokyo: Univ Park Press 1974; 16: 194.

\section{E. Editor(s), compiler(s) as authors:}

- Firkin F, Chesterman N, Penington D, Bryan R, editors. De Gruchy's Clinical Haematology in Medica Practice (5th ed.) Oxford: Blackwell Science 1989.

\section{F. Corporate Author in Book:}

- Verginia Law Foundation. The medical and legal implications of AIDS. Charlottesville: The Foundation 1987.

\section{G. Chapter in Book:}

-Nimmannitya S. Dengue and dengue haemorrhagic fever. In Cook G, editor. Manson's Tropical Diseases (5th ed._London: WB Saunders 1996: 721-9.

\section{H. Scientific and Technical Report:}

- WHO. Control of the leishmaniasis 1990, Technical Report Series 793.

\section{Papers accepted for publication:}

- Hirai K, Takagi E, Okuno Y, Nagata K, Tamura T, Rai SK, Shrestha MP. Status of polyunsaturated fatty acids in serum of persons aged 10-72 in Nepal. Nutr Res (in press).

7. Tables: Tables should be typed in separate page and should be typed in double space. Tables should not be typed in double space. Tables should not be submitted as photographs. Tables should be numbered consecutively in the order of their first citation in the text. Each table should be supplied with a brief title. Any explanatory matter should be placed in footnotes and should be indicated by symbol. Tables should also contain statistical measure (for example, $\mathrm{P}$ values).

8. Illustrations: Figures should be drawn professionally. Photographs should be sharp (contrast) and be in black and white (usually 5x 7 inches). Letters, numbers and symbols should be clear and even throughout and of sufficient size so that it will still be legible when reduced. Title and detailed explanation, if any, should be in the legends for figures, not on the illustrations themselves. Each figure should be labeled on its back indicating the Fig. No., author's name and top of the figure. The figures should not be identifiable unless it is accompanied by written permission of the subject. Figures should be numbered consecutively in the order of their first citation in the text.

9. Units of Measurements: Measurements of length, height, weight and volume should be reported in metric units. Temperature should in degree Celsius.

10. Abbreviations: Only the standard abbreviations should be used. Abbreviations should be avoided in the Title and Abstract.

11. Reprints: Reprints will be available on request made in advance at the time of acceptance of manuscript. For the charge, author (S) should contact the Editor. 